\title{
THE RELATIONSHIP BETWEEN THE TEACHERS' LEVELS OF USE AND THEIR DEMOGRAPHIC CHARACTERISTICS IN THE ADOPTION OF THE STUDENT-ACTIVE LEARNING APPROACH IN EFL CLASSROOMS IN OMAN: A QUANTITATIVE AND EXPLORATORY RELATIONAL STUDY
}

\author{
Bati Al Shekaili* \\ *Dr., Sultan Qaboos University, Sultanate of Oman, shkailibati@hotmail.com
}

\begin{abstract}
Shifting from the traditional teacher-centered to the innovative student-centered educational philosophy in English as a Foreign language (EFL) classrooms represented in the adoption of the student-active learning (SAL) approach has been quite extensively implemented as a valuable approach towards effective students' language learning. An exploratory study was carried out to investigate the teachers' actual Levels of Use (LoU) in the adoption of the SAL approach in their classrooms and its relationship with their demographic variables including gender, age, teaching experience, educational qualifications, and nationalities. The research design was quantitative and exploratory relational. A number of 505 English language teachers participated in this study. Data was collected through a questionnaire including two parts: demographic data and the Levels of Use Self-Assessment (LoU-SA) questionnaire. This was to obtain a holistic picture of the teachers' LoU pertaining to the SAL approach adoption and their demography. The descriptive statistical analyses as well as the symmetric measure of association of Cramer's $V$ were used to analyze the data. The results indicated that the majority of the teachers were at the Refinement Level (IVB), and equally at the Preparation Level (II), the Mechanical Use Level (III), and the Routine Level (IVA). It was also found that there were positive relationships between the teachers' LoU and their demographic characteristics. Based on these research findings, it was recommended, among others, that different interventions including training, support, and sufficient teaching materials should be offered. More collaborative opportunities between teachers from different demographic groups should be encouraged, too.
\end{abstract}

Keywords: Relationship, Levels of Use (LoU), Demographic Characteristics, Adoption, Student-Active Learning (SAL), English as a Foreign Language (EFL), Innovation.

\section{INTRODUCTION}

A number of claims have been made on the value of adopting student-centered educational philosophy in English as Foreign Language (EFL) classrooms (Nunan, 2005). Learning instructions must be centered on the student and an ongoing process grounded in experience (Watkins et al., 2007). Students, not the subject matter, must remain the focus throughout the educational system (Rinaldo, 2004). Students must be the core component in the learning process, and should be engaged in critical thinking activities (Prince, 2004). 
These activities involve crucial new approaches and explorations, such as solving complex, real-world problems (Tempelaar, 2006).

In particular, the Student-Active Learning (SAL) approach has been widely evident and is significantly important for the mastery of various skills, enabling students to think critically and solve complex problems, and contributing opportunity of carrying on to course completion (Braxton et al., 2008). Adopting the SAL approach is viewed to be critical for students to show their underlying capabilities and upgrade them gradually which then help them be more engaged in the process of acquiring knowledge rather than placing undue emphasis on the complete product (Rinaldo \& Denig, 2009).

\section{THE STUDENT- ACTIVE LEARNING APPROACH}

Much literature has dealt with the concept of the SAL approach as it becomes a favorable aspect to change the traditional teacher-centered classrooms into newer student-centered approach towards students' learning (Van De Bogart, 2009). This is by instilling in students as a sense of self-discovery without losing the basic tenants of educational taxonomy or a rigorous understanding of the foundation and development of the academic disciplines the students may be studying and need to learn students' learning (Van De Bogart, 2009).

The SAL approach, as pointed out by (McKinney, 2011), refers to learning activities where students accomplish and participate rather than just listening to a lecture. In these activities, students are doing something such as self-discovering, processing, and applying information (McKinney, 2011). Such activities, as stated by Chickering and Gamson (1987, cited in Pedersen, 2010), adopt the talking-through process, writing about, and course material application to the students' daily lives. Such activities need students to have more interaction with their peers and their teachers where feedback is directly given as well as selfexperience related to course material is well used (Holtzman, 2005, cited in Pedersen, 2010). In this matter, the SAL approach inspires the students into self-analysis and expression (Van De Bogart, 2009), and enhances students' theoretical understanding and thinking skills through problem-solving as they collect, analyze, interpret and represent data (Pundak et al., 2009).

\section{THE LEVELS OF USE}

Understanding and systematically addressing the importance of documenting the level of adopting innovations is an area, which has been neglected by many researchers (Hall et al., 2008). The majority of such innovations have been proposed either to be adopted or they are not. In such contexts, the LoU construct is significant in educational research as it provides the conceptual framework for examining the user/non-user of innovations. This is also because it does not have to be redefined for every innovation. Additionally, it can be used in any organization and with first-order as well as second-order innovation.

The LoU, as stated by Hall et al. (2008), are distinct states that represent observably different types of behavior and patterns of innovation use as exhibited by individuals and groups. These levels characterize a user's development in acquiring new skills and varying the use of the innovation. Each level encompasses a range of behaviors.

Eight distinct levels have been identified by the LoU researchers to help explain behaviors exhibited by participants involved in adopting innovations. Each level is independent of the others, and although they appear to be sequential, each level should be treated as discrete and unique. Progression from one level to the next is marked by key decision points and corresponding behaviors in several domains: knowledge, acquiring information, assessing, sharing, planning, status reporting, and performing (Anderson, 1997).

The LoU, as stated by Hall and Loucks (1977), illustrate the users and the nonusers of an innovation. They illustrate the changes in behavior that individuals show when they are shifting through their adoption of the innovation (Al Aghbari, 2007), and show a continuum of growth gradually moving from not using the innovation towards using different skills, experiences, and looking for various ways to modify the existing innovation (Berg, 1993, cited in Mustafa, 2010). They, as summarized by Hall and Loucks (1977), permit an operational, cost-feasible explanation and certification of whether or not an innovation or treatment is being adopted. They added that data from research of change and evaluation studies showed that the LoU could be reliably measured. They also added that knowing the LoU of individuals within a research or evaluation sample could avoid holding false assumptions and making misleading interpretations about the user or nonuser and the effects of the treatment or innovation under study .

One of the established methods for measuring the LoU is a focused interview protocol that has been research verified and applied in many studies (Hall \& Loucks, 1977; Hall, Dirksen \& George, 2006, cited in 
Hall, 2010). The LoU, as proposed by Hall et al. (1973), is divided into eight levels divided into two main levels. The nonuse level is located at the bottom and includes three levels in hierarchical order including Non-use, Orientation, and Preparation. The use level is located at the top and includes the other five levels in hierarchical order including Mechanical Use, Routine, Refinement, Integration, and Renewal (Hall \& Hord, 2011).

The Renewal Level $(\mathrm{VI})$ refers to the state in which the user re-evaluates the quality of use of the innovation, seeks major modifications of or alterations to present innovation to achieve increased impact on clients, examines new developments in the field, and explores new goals for self and the system. The Integration Level (V) refers to the state in which the user is combining own efforts to use the innovation with related activities of colleagues to achieve a collective impact on clients with their common sphere of influence. The Refinement Level (IVB) refers to the state in which the user varies the use of the innovation to increase the impact on clients within immediate sphere. Variations are based on knowledge of both shortterm and long-term consequences for clients. The Routine Level (IVA) refers to the state in which the use of the innovation is stabilized. Few if any changes are being made in ongoing use. Little preparation or thought is being given to improving innovation user or its consequences. The Mechanical Use Level (III) refers to the state in which the user focuses most effort on the short-term, day-to-day use of the innovation with little time for reflection. Changes in use are made more to meet user needs than client needs. The user is primarily engaged in a stepwise attempt to master the tasks required to use the innovation, often resulting in disjointed and superficial use. The Preparation Level (II) refers to the state in which the user is preparing for the first time use of the innovation. The Orientation Level (I) refers to the state in which the user has recently acquired or is acquiring information about the innovation and/or has recently explored or is exploring its values orientation and its demands upon user and user system. The Non-use Level (0) refers to the state in which the user has little or no knowledge of the innovation, no involvement with the innovation, and is doing nothing towards becoming involved.

\section{THE TEACHERS' DEMOGRAPHY}

Shao (2004, citing Pierce, 1981) stated that both teachers' age and educational level are major influencing factors affecting teachers' acceptance or rejection of innovation adoption. The findings of the study emphasized that younger teachers with higher levels of education were more likely to adopt innovation.

Salvano-Pardieu et al. (2009) investigated factors such as teachers' age, gender, and teaching level in terms of primary or secondary school and they found that there was a main effect of age, and specific differences of teachers according to gender and teaching level.

Maphalala (2006) found that teachers' age, teaching experience and qualification had an influence on the nature of teachers' experiences in curriculum adoption. However, their last finding showed that teachers' gender, age, teaching experience, and qualification had no influence on the extent to which educators generally found adopting the curriculum to be stressful.

Altrichter $(2005$, citing Fullan, 1991; 1994) categorized the factors affecting innovation adoption into four main categories: characteristics of the innovation itself in terms of perceived or felt need, clarity about goals and means, complexity, quality, contextual suitability and practicality; local characteristics in terms of regional administration like school district, community characteristics, and contextual stability; organization characteristics in terms of management, peer relationships, teachers characteristics and orientations; and government and external agencies characteristics in terms of quality of relationships between central and local actors resource support and training.

Norris and Briers (1989), in their study on the correlation between teachers' personal characteristics and perceptions towards curriculum change, indicated four definite trends. The first trend was experience represented in age, teaching years and tenure at present school was negatively related to teachers' perceptions of effects on enrolment. As these elements increased, perceptions became more negative towards the proposed change. However, a positive relationship existed between tenure variables and perceptions towards in-service needs resulting from the change. The second trend was the number of schools in which the teachers had worked was inversely related, with negative correlation existing for number of schools and the perceptions concerning the change process. The more schools at which the teachers had taught, the more negative were their perceptions towards the curricular changes being proposed. The third trend was the number of years spent in pre-service training as a student and years spent as an employee were negatively related to teacher perceptions. The more time spent as a student in preservice training and as an employee, the more negative were the perceptions of the teachers. The final trend was the relationships between level of education and teachers' perceptions of the effects of change were 
inconclusive. There was little evidence to suggest that the educational level of teachers was a major influencing factor in how teachers perceived the changes in curriculum.

However, Van Braak et al. (2004), in their study, suggested that the effect of technological innovativeness on class use of computers was more significant than personal factors such as age, gender, computer attitudes, and computer experience. The importance of the concept of innovativeness as a contributor was to explain different levels of computer use.

Reviewing the literature suggests that there are many demographic variables that affect the teachers' decision to adopt or not to adopt innovations in their classroom (Lau et al., 2005; Maphalala, 2006; Avramidis \& Kalyva, 2007; Kumar et al., 2007; Meelissen \& Drent, 2008; Salvano-Pardieu et al., 2009). Seven of the most often-used variables are age, gender, teaching experience, attitudes, beliefs, academic contexts, and academic qualification. However, five variables were investigated in this study. They were gender, age, teaching experience, qualification, and nationality.

In this study, five demographic characteristics were determined. The gender variable is used to find out if it has relationship with the teachers' LoU of the SAL approach adoption based on male and female teachers. The age and teaching experience variables are selected for consideration to determine if they have relationships with teachers' LoU of the SAL approach adoption based on the younger and the more senior teachers, or the less experienced teachers and the more experienced teachers. The qualification variable is chosen to know if it has relationship with teachers' LoU of the SAL approach adoption based on the less qualified teachers and the more qualified teachers. The nationality variable is used to determine whether it has relationship with teachers' LoU of the SAL approach adoption based on the teachers from different cultural background.

\section{METHODOLOGY}

Quantitative research method was used in this study. It was collected through Mustafa's (2008) adaptive Level of Use Self-Assessment (LoU-SA) questionnaire. 505 teachers participated in this study. For the purpose of this study, descriptive statistical analyses were first used to find out the frequencies and percentages. The symmetric measure of association of Cramer's $V$ was also used as descriptive statistical tool to determine the relationships between variables (De Vaus, 2013). Such statistical tool was used to understand the relationship between two or more discrete variables of interest. It is to identify if there were relationships between the teachers' LoU (ordinal data) and their demography (categorical data). The relationships were determined on values from -1 to +1 indicating the strength and direction of the relationship, i.e., a positive $(+1)$ or a negative $(-1)$ correlation or a zero/no correlation at all (0) (De Vaus, 2013). These relationships were considered as very weak relationships for the values, which were less than + or -0.10 , weak relationships for the values, which were from + or -0.10 to 0.19 , moderate relationships for the values, which were from + or -0.20 to 0.29 , and strong relationships for the values, which were + or -0.30 or above.

\section{FINDINGS AND DISCUSSION}

\subsection{The Teachers' Levels of Use}

The findings of the study based on the LoU-SA showed that in the adoption of the SAL approach in EFL classrooms the majority of teachers $(n=180)$ were at the Refinement Level (IVB).

Table 1. Frequencies and Percentages of the teachers' Levels of Use Self-Assessment

\begin{tabular}{|c|c|c|c|}
\hline \multicolumn{2}{|c|}{ Levels of Use } & N & $\%$ \\
\hline II & Non-Use & 14 & 2.8 \\
II & Orientation & 22 & 4.4 \\
III & Preparation & 12 & 2.4 \\
IVA & Mechanical Use & 43 & 8.5 \\
IVB & Routine & 52 & 10.3 \\
V & Refinement & 180 & 35.6 \\
VI Integration & 96 & 19.0 \\
\hline \multicolumn{2}{|c|}{ Total } & 86 & 17.0 \\
\hline
\end{tabular}

These findings are in line with the previous studies of Al Aghbari (2007), Mustafa $(2010 ; 2012)$ and 
Nestler-Rusack (2011). Al Aghbari (2007) found that the majority of teachers were at the Mechanical Use and the Routine Levels. Mustafa $(2010 ; 2012)$ found that majority of the English language teachers were at the Mechanical Use and the Refinement Levels. Nestler-Rusack (2011) found that the majority of participants were independently implementing educational innovation, which reflected a Refinement LoU.

Accordingly, as mentioned by Hall and Hord (2011), the teachers who were at the Preparation Level (II) had already decided to use the innovation and scheduled a specific time to start using it. They had not started yet, but the intention and a specific start-up time was indicated by them. They were studying and preparing materials for its first use.

The teachers who were at the Mechanical Use Level (III) were disjointed and inefficient. They continuously had a day-to-day and minute-to-minute planning. They made adaptations in managing time, materials, and other resources. They focused on short-term, day-to-day planning and using of the innovation. They also made adaptations in their use or in the innovation itself in order to increase their own benefits and to master it.

The teachers who were at the Routine Level (IVA) had already mastered the innovation and its use and established a regular way of working with it. They did not plan to make any adaptations or changes otherwise; their use was stabilized, as they believed that their work is fine.

The teachers who were at the Refinement Level (IVB) made reflections and assessments on their use of the innovation and made adaptations to their use with the intention of increasing their students' benefits rather than their own benefit.

A number of teachers were at the Integration Level (V) based on the LoU-SA. This actually reflects that the teachers preferred to work independently and in isolation. To overcome such situation, it is suggested that officials and decision-makers should offer more personal development programs to foster collaboration strategies in order to encourage those teachers to collaboratively work with others especially those who came from different cultural backgrounds. This may help, on the one hand, to reduce teachers' professional isolation (Sindberg \& Lipscomb, 2005) and, on the other hand, to increase the effectiveness of the SAL approach adoption.

A number of teachers were also at the Renewal Level (V) based on the LoU-SA. This mainly reflects two major aspects. First, the teachers might not have the time or the effort to modify the use of the SAL approach or to reflect upon it, as they were busy with daily issues. Second, they might not see the significant need for its modification.

Taking into account of the small number of teachers at the Integration and the Renewal levels, it is assumed that this occurred because of three major reasons. Firstly, the adoption of the SAL approach was not seriously taken by both administrators and teachers across Oman. Secondly, such adoption by the teachers was not regularly assessed in order to come up with constructive feedback. Finally, teachers might not be motivated enough and have inadequate professionalism. These were three major reasons that might discourage the teachers from advancing from the Integration Level to the Renewal Level of Use in the adoption of the SAL approach. Those teachers who were at the Integration and Renewal Levels of Use, as argued by Hall and Hord (2011), were the most important ones, the active ones, and the success of innovation depends mainly on them. However, in this study, they only represented altogether about one third of the participants $(n=182)$.

Some teachers were still at the Non-Use Level (0) based on the LoU-SA. This might reflect that those teachers felt quite insecure, uncertain, unclear and not confident to adopt the SAL approach. According to Hall et al. (2008), teachers at this level were hesitant to read about the innovation and they were also hesitant to attend any offered orientation programs related to the innovation. They were very resistant to change. To reduce the number of teachers who were at the Non-Use Level, it is suggested that the managements should design and deliver various interventions that stimulate teachers' interest, motivate them, and support their movement to learn more about the innovation (Hall \& Hord, 2011).

Some teachers were also still at the Orientation Level (I) based on the LoU-SA. The teachers who were at this level might start learning about the innovation by attending overview sessions about the innovation and inquiring related information from others (Hall et al., 2008). It is suggested that the managements should offer those teachers with more interesting information and encouraging support towards the effective adoption of the SAL approach (Hall \& Hord, 2011).

Levels of Use, as claimed by Hall et al. (2008), can serve a valuable diagnostic tool for planning and facilitating the smooth adoption of innovation. In this regard, Hall and Hord (2011) insisted that each individual's LoU and success with innovation is in a large measure affected by the facilitation he/she 
receives. The superficial knowledge base of the facilitators can provide only superficial support to the adoption of the user of the innovation. Consequently, those facilitators may then have an idea of the daily challenges faced by the teachers in the adoption of the SAL approach in order to move ahead in their LoU. This understanding and appreciation of the teachers' daily challenges may help facilitators to design and run staff development programs and other related sessions with those challenges in mind towards a better educational innovation adoption with greater reliability and competency (Hall et al., 2008).

Additionally, LoU data, as stated by Marsh (1988), offers significant input on the type of support needed by individual teacher to achieve higher levels of educational innovation adoption. The findings of LoU in this study can be helpful for facilitators to propose timely specific support to EFL teachers. For example, facilitators can support teachers who were at the Preparation Level (II) to move ahead to the Mechanical Use Level (III) by being supportive to teachers as much as possible, providing them with ongoing assistance to help them proceed ahead to the next level as efficiently and smoothly as possible (Hall \& Hord, 2011).

To support the previous discussion, much research was done on the context of LoU of educational innovation adoption (Rutherford \& Loucks (1979), Rutherford (1981), Dudderar (1997), Richmond-Cullen (1999), Basinger (2000), Hall et al. (2008), Tunks \& Weller (2009) and Orr \& Mrazek (2009). For example, Rutherford and Loucks (1979) and Rutherford (1981) claimed that individual's LoU of innovation should be the main concern in order to assess the innovation being used. Dudderar (1997), Richmond-Cullen (1999) and Basinger (2000) mentioned that ongoing professional development programs should always be there to mainly support the adoption of educational innovation, i.e., teachers who were at the three levels of NonUse, i.e., Non-Use Level (0), the Orientation Level (I) and the Preparation Level (II), can be quite easily facilitated to the Mechanical Use Level (III) and the Routine Level (IVA) through professional development sessions. Hall et al. (2008) suggested that the innovation adoption is mainly affected by the teachers themselves, their administrators, the environment and the feedback received on the innovation itself. Tunks and Weller (2009), based on interview findings, claimed that the teachers who received more ongoing support had higher LoU whereas the ones who received only initial support such as initial professional development programs had lower LoU.

\subsection{The Relationships between the Teachers' Levels of Use and Demography}

The levels of the SAL approach use were often related to teachers' demographic profile. Some researchers claimed that teachers' demography could influence the teachers' actual adoption of the SAL approach, while others believed that there was no relationship between these two variables. In order to examine the relationship between teachers' LoU and their demography, the statistical measure of association of Cramer's $\checkmark$ was employed. The following subsections aim to discuss the correlation occurred between these variables.

\subsubsection{Teachers' Levels of Use and Gender}

The findings indicated a weak, positive relationship between the teachers' LoU and their gender in the adoption of the SAL approach. This means that there was correlation between teachers' levels of the SAL approach use and their gender.

Table 1. Cramer's V for the Relationship between the Teachers' LoU and Gender

\begin{tabular}{|c|c|c|}
\hline \multicolumn{2}{|l|}{} & Value \\
\hline Nominal by Nominal & Phi & .126 \\
\hline & Cramer's V & .126 \\
\hline \multicolumn{2}{|c|}{ N of Valid Cases } & 505 \\
\hline
\end{tabular}

This finding is aligned to the studies by Blackwood (2002), Al Aghbari (2007), Salvano-Pardieu et al. (2009), and Rahimi and Fatemeh (2012). Blackwood (2002) found that female teachers had higher levels of innovation use than male teachers did. Al Aghbari (2007) found that female teachers had a higher mean score than male teachers. Salvano-Pardieu et al. (2009) found that gender had a main influence on teachers' level of innovation adoption. Rahimi and Fatemeh (2012) found that there was correlation between teachers' actual innovation use and their gender. They found that male teachers and female teachers were different in adopting the SAL approach activities.

However, this is contradicted to the studies by Marcinkiewicz (1994), Law (2002), Zea (2004), and Maphalala (2006). Marcinkiewicz (1994) found that both male teachers and female teachers were alike in the 
innovation LoU. Law (2002) found that there was no relationship between level of innovation use and their gender, i.e., male and female teachers had similar LoU. Zea (2004) found that there was no correlation between teachers' gender and their LoU. That is, there was an indicator that both male and female teachers progressed to higher LoU, were required to collaboratively work with others to gain more impact in the use of the innovation, and developed new ideas to effectively refine the existing innovation in their teaching. Maphalala (2006) found that gender had no influence on teacher' level of innovation adoption, i.e., both males and females had similar influence.

Since the relationship between the teachers' LoU and their gender was positive, this implies that teachers' gender was positively related to their LoU of the SAL approach. This also means that the upgrade of their LoU was related to their gender. This implies that whether the teachers are men or women they may have different LoU of the SAL approach. It is suggested that both male and female teachers should be more encouraged, motivated, and praised by their managements to attend more professional development sessions. Follow-up sessions should also be conducted for them to guarantee an effective adoption of the SAL approach.

\subsubsection{Teachers' Levels of Use and Age}

The findings indicated a weak, positive relationship between the teachers' LoU and their age in the adoption of the SAL approach. This means that the teachers' age was considered to be correlated to the levels of the SAL approach use.

Table 2. Cramer's $\vee$ for the Relationship between the Teachers' LoU and Age

\begin{tabular}{|c|c|c|}
\hline \multicolumn{2}{|c|}{} & Value \\
\hline Nominal by Ordinal & Phi & .276 \\
\hline & Cramer's V & .159 \\
\hline \multicolumn{2}{|c|}{ N of Valid Cases } & 505 \\
\hline
\end{tabular}

This is inconsistent with the studies by Van Braak et al. (2004), Maphalala (2006), and Chan (2008). Van Braak et al. (2004) found that age factor had no relationship with the teachers' level of innovation use. Maphalala (2006) found that age group did not relate to teacher' level of innovation adoption. Chan (2008) found that the relationship between teachers' actual classroom actions and their age did not exist. This revealed that teachers in different age groups did not have different mean scores in their levels of innovation use.

Since the relationship between the teachers' LoU and their age was positive, this implies that teachers' age was positively related to their LoU of the SAL approach. In other words, as the teachers get older, their LoU of the SAL approach upgrade to higher levels. The findings specifically revealed that teachers aged 4049 represented the biggest group in most of the levels except the levels of Non-Use and Mechanical Use that were represented by teachers aged 30-39. The biggest number of teachers aged 40-49 was in the Refinement Level whereas the biggest number of teachers aged 30-39 was in the Mechanical Use Level. It is assumed that those groups of teachers played a big role in the SAL approach adoption. They had quite enough experience in the SAL approach adoption where they could self-evaluate their current LoU from time to time and tried to come up with better modifications towards innovation adoption. They could also continuously support younger teachers by offering them enough input towards the SAL approach adoption. Those teachers were also the most respectful ones by younger teachers; therefore, they might influence others to effectively adopt the SAL approach. This assumption confirms that age was considered as an influential factor on teachers' LoU.

\subsubsection{Teachers' Levels of Use and Teaching Experience}

The findings indicated a weak, positive relationship between the teachers' LoU and their teaching experience in the adoption of the SAL approach. This means that teachers' teaching experience was related to their LoU of the SAL approach.

Table 3. Cramer's $V$ for the Relationship between the Teachers' LoU and Teaching Experience

\begin{tabular}{|c|l|c|}
\hline \multicolumn{2}{|c|}{} & Value \\
\hline Nominal by Ordinal & Phi & .254 \\
\hline & Cramer's V & .147 \\
\hline \multicolumn{2}{|c|}{ N of Valid Cases } & 505 \\
\hline
\end{tabular}

This is consistent with the studies by Zea (2004) and Chan (2008). Zea (2004) found that the more 
experienced teachers had the highest LoU. The findings indicated that the more experienced group was able to progress to the Renewal Level (VI). Chan (2008) found that the relationship between EFL teaching experience and their actual innovation use was statistically measured. This revealed that teachers in the four groups with different years of EFL teaching experience had different mean scores in the level of adoption of the innovation.

Since the relationship between the teachers' LoU and their teaching experience was positive, this implies that teachers' teaching experience was positively related to their LoU of the SAL approach. In other words, as the teachers become more experienced, their LoU's of the SAL approaches upgrade to higher levels. The findings revealed that teachers who had more than 15 years of teaching experience were the biggest group in all LoU. The biggest number of this group was in the Refinement Level. This group of teachers had a great role in the adoption of the SAL approach. It seems that those teachers were enthusiastically seeking other notions and methods to enhance the SAL approach adoption. By doing so, they would effectively influence other teachers in other teaching experience groups to actively collaborate and cooperate with them to accomplish more impact in the use of the SAL approach.

\subsubsection{Teachers' Levels of Use and Qualification}

The findings indicated a weak, positive relationship between the teachers' LoU and their qualification in the adoption of the SAL approach. This means that qualification had relationship with teacher' LoU of the SAL approach.

Table 4. Cramer's V for the Relationship between the Teachers' LoU and Qualification

\begin{tabular}{|c|l|c|}
\hline \multicolumn{2}{|c|}{} & Value \\
\hline Nominal by Nominal & Phi & .193 \\
\hline & Cramer's V & .136 \\
\hline \multicolumn{2}{|c|}{ N of Valid Cases } & 505 \\
\hline
\end{tabular}

This finding is aligned to the findings of the studies by Maphalala (2006) and Al Aghbari (2007). Maphalala (2006) found that qualification groups had weak relationship with the teacher' level of innovation adoption. Al Aghbari (2007) found that there was weak relation between teachers' qualification groups and their level of innovation use.

Since there was positive relationship between the teachers' LoU and their qualification, this implies that the teachers' qualification was positively related to their LoU of the SAL approach. It means that teachers being more qualified tend to upgrade their LoU of the SAL approach. It is suggested that the managements should encourage, motivate, and support teachers in different groups to effectively adopt the SAL approach.

\subsubsection{Teachers' Levels of Use and Nationality}

The findings indicated a moderate, positive significant relationship between the teachers' LoU and their nationality in the adoption of the SAL approach. It implies that teachers' nationality groups had relationship with the teachers' level of innovation use.

Table 5. Cramer's V for the Relationship between the Teachers' LoU and Nationality

\begin{tabular}{|c|l|c|}
\hline \multicolumn{2}{|c|}{} & Value \\
\hline Nominal by Nominal & Phi & .536 \\
\hline & Cramer's V & .203 \\
\hline \multicolumn{2}{|c|}{ N of Valid Cases } & 505 \\
\hline
\end{tabular}

The findings specifically revealed that teachers from India and teachers from Oman represented the biggest group in half of the levels each. Indian teachers represented the biggest group in Orientation, Refinement, Integration, and Renewal Levels while Omani Teachers represented the biggest group in NonUse, Preparation, Mechanical Use, and Routine Levels. The highest number of Indian teachers was in the Refinement Level, whereas the highest number of Omani teachers was in the Mechanical Use Level.

Since the relationship between the teachers' LoU and their nationality was positive, this implies that teachers' nationality was positively related to their LoU of the SAL approach. Teachers who come from various cultural backgrounds may have different LoU of the SAL approach. It is assumed that those two nationality groups, Indians and Omanis, had more knowledge and awareness concerning the adoption of the SAL approach. They might have more opportunities for professional development in Oman or before coming to Oman for the Indian ones. As those teachers were highly knowledgeable of the SAL approach adoption, 
they might support other teachers to effectively incorporate the innovation of the SAL approach in their own classrooms. By having more professional commitments, they might also push themselves and others towards higher levels of the SAL approach adoption.

\section{REFERENCE LIST}

Al Aghbari, S. Y. (2007). Teachers' concerns and levels of use in the adoption of student-centered teaching approach: A study of social studies teachers in Oman. Unpublished PhD thesis, Universiti Sains Malaysia.

Anderson, S. (1997). Understanding teacher change: Revisiting the concerns-based adoption model. Curriculum Inquiry, 27(3), 331-367.

Avramidis, E., \& Kalyva, E. (2007). The influence of teaching experience and professional development on Greek teachers' attitudes towards inclusion. European Journal of Special Needs Education, 22(4), 367-389.

Basinger, D. S. (2000). Utilization and integration of technology by teachers: A case study. Louisiana Tech University.

Braxton, J. M., Jones, W. A., Hirschy, A.S., \& Hartley, H.V., III. (2008). The role of active learning in college persistence. New Directions for Teaching and Learning, 115, 71-83.

De Vaus, D. A. (2013). Survey in Social Research (6 $6^{\text {th }}$ ed.). London: Routledge.

Dudderar, D. (1997). Measuring teachers' level of use of Mathematics: Their Way K-2. Wilmington College, New Castle, DE.

Hall, G.E. (2010). Technology's Achilles heel: Achieving high-quality implementation. Journal of Research on Technology in Education, 42(3), 231-253.

Hall, G. E., \& Hord, S. M. (2011). Implementing change: Patterns, principles and potholes (3rd ed.). Upper Saddle River, New Jersey: Pearson.

Hall, G. E. and Loucks, S. F. (1977). A developmental model for determining whether the treatment is actually implemented. American Education Research Journal, 14 (3), 263-76.

Hall, G. E., Wallace, R. D. Jr., \& Dossett, W. A. (1973). A developmental conceptualization of the adoption process within educational institutions (Report No. 3006). Austin: Research and Development Center for Teacher Education.

Hall, G. E., Dirksen, D. J., \& George, A. A. (2008). Measuring implementation in schools: Levels of Use. Austin, TX: Southwest Educational Development Laboratory.

Kumar, V., Mukerji, B., Butt, I., \& Persaud, A. (2007). Factors for successful e- government adoption: A conceptual framework. Electronic Journal of e-Government, 5(1), 63-76.

Lau, P., Yuen, M., \& Chan, R. (2005). Do demographic characteristics make difference to burnout among Hong Kong secondary school teachers? Social Indicator Research, 71, 491-516.

Maphalala, M.Ch. (2006). Educators' experiences in implementing the revised national curriculum statement in the get band. Unpublished PhD Thesis, University of Zululand.

Marcinkiewicz, H.R. (1994). Computers and teachers: Factors influencing computer use in the classroom. Journal of Research on Computing in Education, 26 (2), 220-237.

Marsh, C. J. (1988). Curriculum implementation: An analysis of the use of the Concerns-Based Adoption Model (CBAM) in Australia, 1981-87. Curriculum Perspectives, 8(2), 30-42.

McKinney, K. (2011). Active learning. The Illinois State University, Center for Teaching, Learning, \& Technology. Retrieved October 1, 2011, from http://www.cat.ilstu.edu/additional/tips/newActive.php

Meelissen, M. R. M., \& Drent, M. (2008). Gender differences in computer attitudes: Does the school matter? Computers in Human Behavior, 24, 969-985.

Mrazek, R. and Orr, D. (2009). Assessing the professional growth of post-secondary students studying the education applications of emergent technologies. Revista de Informatica Applicada. Brazil- Journal of Applied Computing, 5(1), 5-13.

Mustafa, Z. (2008) Teachers' Levels of Use in the Adoption of Task-Based Language Teaching in the 
Classrooms. Unpublished Ed.D Thesis. Universiti Sains Malaysia.

Mustafa, Z. (2010). Teachers' levels of use in the adoption of task-based language teaching in Malaysian classrooms. The International Journal of Interdisciplinary Social Sciences, 5(3), 127-137.

Mustafa, Z. (2012). Teachers' encountered challenges in the adoption of task-based language teaching in Malaysian classrooms. The International Journal of Arts and Sciences, 5(3), 269-279.

Nestler-Rusack, D. (2011). School personnel's reports of inclusive educational practice within their School, and their concerns about and use of inclusive educational practice. Unpublished PhD thesis. University of Hartford.

Nunan, D. (2005). Important tasks of English education: Asia-wide and beyond. Asian EFL Journal, 7 (3).

Pedersen, D. (2010). Active and collaborative learning in an undergraduate sociological theory course. Teaching Sociology, 38(3), 197-206.

Prince, M. (2004). Does active learning work? A review of the research. Journal of Engineering Education, 93 (3), 223-231.

Pundak, D., Herscovitz, O., Shacham, M., Weizer-Biton, R. (2009). Instructors' attitudes toward active learning. Interdisciplinary Journal of E-Learning and Learning Objects, 5, 215-232.

Richmond-Cullen, C. A. (1999). An evaluation of how teachers implement training received in an intensive arts staff development program. Temple University.

Rinaldo, V. (2004). Subject matter is the vehicle and not the focus of learning. Music Educators Journal, 45(3), 31-34.

Rinaldo, V., \& Denig, S. (2009). A Constructivist approach to learning music: What role, if any, does active engagement play in the learning process?

Rutherford, W. L. (1981). Team teaching: How do teachers use it? Revised. Austin, TX: Research and Development Center for Teacher Education, the University of Texas.

Rutherford, W. L., \& Loucks, S. F. (1979). Examination of the implementation of a junior high school's new approach to discipline by longitudinal analysis of change in teachers' Stages of Concern and Levels of Use. Paper presented at the Annual Meeting of the American Educational Research Association, San Francisco.

Salvano-Pardieu, V., Fontaine, R., Bouazzaoui, B., \& Florer, F. (2009). Teachers' sanction in the classroom: Effect of age, experience, gender, and academic context. Teacher and Teacher Education, 25, 1-11.

Shao, X. (2004). Teacher training and curriculum reform in Chinese agricultural schools. Unpublished PhD Thesis, The Pennsylvania State University.

Sindberg, L., \& Lipscomb, S.D. (2005). Professional isolation and the public school music teacher. Bulletin of the Council for Research in Music Education, 166, 43-56.

Tempelaar, D. T. (2006). The role of metacognition in business education. Industry and Higher Education, 20(5), 291-297.

Tunks, J., \& Weller, K. (2009). Changing practice, changing minds, from arithmetical to algebraic thinking: an application of the concerns-based adoption model (CBAM). Educational Studies in Mathematics, 72(2), 161-183.

Van Braak, J., Tondeur, J., \& Valcke, M. (2004). Explaining different types of computer use among primary school teachers. European Journal of Psychology of Education, 19(4), 407-422.

Van De Bogart, W. G. (2009). Active learning pedagogy: A new teaching methodology for a new generation of teachers. Retrieved October 1, 2011 from Nakhon Swan Rajabhat University. Available at http://www.southeastasianreview.com/Active\%20learning\%20Pedagogy.pdf

Watkins, C., Carnell, E., \& Lodge, C., (2007). Effective learning in classrooms. California: Sage Publications.

Zea, G. (2004). The concerns and levels of use of Sixth Form Geography teachers in implementing the new Sixth Form Geography curriculum. Jurnal Penyelidikan MPBL, Jilid 5. 